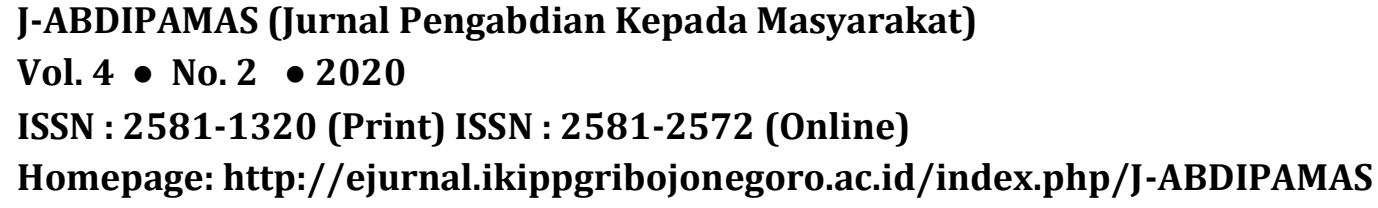

ISSN : 2581-1320 (Print) ISSN : 2581-2572 (Online)

Homepage: http://ejurnal.ikippgribojonegoro.ac.id/index.php/J-ABDIPAMAS

\title{
GERAKAN GURU MENULIS BUKU MELALUI PELATIHAN ONLINE DENGAN MICROSOFT TEAMS BAGI GURU SE KOTA SALATIGA
}

\author{
Suranto \\ Universitas Muhammadiyah Surakarta. E-mail: sur122@ums.ac.id
}

\begin{abstract}
The recent problems of teacher, among other, is the productivity of writing a book. There are many obstacles that teacher faces, among them, mostly, are the lack of motivation and the lack of knowledge of writing a book. The purposes of this service are: 1) to increase teacher's motivation for writing a book, 2) to increase teacher's skill in making a book from a research outcome, 3) to increase teacher's skill in writing a lesson book and an enrichment book, 4) to increase teacher's skill in writing a fiction book, 6) to increase teacher's knowledge of publishing a book. The participants are teachers from all educational levels in Salatiga City amounted to 117 teachers. The method of activity implemented was a Microsoft Teams-aided online training. The training activity included web meeting, discussion, consultation, and assistance for 1 month. The service activity is able to motivate the teachers to write a book based on the right principles of writing a book and to produce a book in accordance with the necessity of the school where the teachers teach.
\end{abstract}

Keywords: online training, writing a book, Microsoft Teams

\begin{abstract}
ABSTRAK
Permasalahan pada guru saat ini diantaranya adalah produktifitas menulis buku, banyak hambatan yang dialami oleh guru utamanya kurangnya motivasi dan pengetahuan menulis buku. Tujuan kegiatan pengabdian ini adalah 1) meningkatkan motivasi guru dalam menulis buku, 2) meningkatkan kemampuan guru dalam membuat buku dari hasil penelitian, 3) meningkatkan kemampuan guru dalam menulis buku mata pelajaran dan buku pengayaan, 4) meningkatkan kemampuan guru dalam menulis buku fiksi, 6) Meningkatkan pengetahuan guru dalam menerbitkan buku. Peserta kegiatan adalah guru dari semua jenjang tingkat pendidikan di Kota Salatiga yang berjumlah 117 guru. Metode kegiatan dilakukan dengan pelatihan online berbantuan Microsoft Teams. Kegiatan pelatihan meliputi web meeting, diskusi, konsultasi, dan pendampingan selama 1 bulan. Kegiatan pengabdian ini telah mampu mendorong guru untuk menulis buku sesuai dengan kaidah penulisan buku yang benar serta menghasilkan jenis buku yang sesuai dengan kebutuhan yang diperlukan di sekolah tempat guru mengajar.
\end{abstract}

Kata Kunci: pelatihan online, penulisan buku, Microsoft Teams

\section{PENDAHULUAN}

Produktifitas guru salah satunya dapat dilihat dari hasil karya tulisnya diantaranya berupa penelitian PTK ataupun terbitan buku. Di Indonesia produktifitas guru menulis sangat rendah, guru-guru lebih memilih menggunakan buku terbitan yang dijual di toko buku untuk pembelajaran (Sofiah dkk, 2019). Buku ajar terbitan nasional dari penerbit yang biasa dipakai secara umum memang memiliki kualitas yang baik, secara menyeluruh mewadahi materi pembelajaran pada umumnya. Tetapi ketergantungan kepada buku yang sudah ada akan berdampak negatif bagi guru dan 
siswa, diantaranya adalah 1) terlalu monotonnya isi buku dapat mengakibatkan batasan pengetahuan yang diajarkan ke siswa 2) buku ajar umum belum tentu sesuai dengan karateristk siswa di sekolah tertentu 3) membuat guru tergantung dan menurunkan motivasi menulis.

Kurikulum K-13 menuntut adanya kemampuan guru untuk dapat membuat dan mengembangkan sendiri bahan ajar maupun media yang sesuai dengan tingkat kompetensi yang ada di masing-masing sekolah (Jauhar, Rukayah, \& Asmah, 2019). Kebutuhan buku bagi siswa seperti buku pengayaan, buku fiksi yang berupa cerpen, novel, atau puisi juga sangat diperlukan, dan masih sangat terbatas kuantitas dan kualitasnya di toko buku. Guru yang memiliki kemampuan akademik di bidang ajarnya dan memiliki pengalaman mengajar setiap hari dapat dijadikan modal penting dalam penulisan buku secara autodidak (Haryati dkk, 2011). Bahan-bahan ajar seperti powerpoint, lembar kegiatan siswa, lembaran modul per pertemuan dapat dijadikan bahan dalam pembuatan buku. Dengan adanya buku karya dari gurunya sendiri akan memberikan semangat dan kebanggaan pada siswa yang menggunakan buku tersebut. Selain itu kebermanfaat menulis buku bagi guru banyak sekali, diantaranya adalah:

\section{Meningkatkan Value Diri}

Dengan menulis buku kemampuan dan kemahiran guru di bidang yang dia miliki akan terakui, buku akan menjadi karya kebanggaan bagi siswa dan guru itu sendiri, serta dapat meningkatkan kepercayaan pada atasan, rekan guru, siswa, dan publik akan penguasaan ilmu dan keprofessionalannya.

\section{Memberikan Sumbangsih Keilmuan}

Dengan guru produktif menulis buku, maka keilmuannya tidak hanya diberikan ke siswanya sendiri tapi juga dapat dimanfaatkan lebih luas ke guru dan siswa dari sekolah lainnya. Kebermanfaatan keilmuan guru juga tiddak akan terputus saat guru sudah tidak aktif mengajar lagi, sehingga dapat diwariskan dari generasi ke generasi.

\section{Passive Income}

Dari penulisan buku, guru mendapatkan tambahan angka kredit poin. Jika buku diterbitkan akan mendapatkan royalti dari penerbit yang diikuti pendapatan lainnya seperti menjadi narasumber atau pembicara, kenaikan pangkat, dan lain-lain.

\section{Manfaat Lainnya}

Manfaat menulis buku diantaranya juga dapat meningkatkan kualitas diri guru, karena penulis akan banyak belajar dan membaca untuk menyelesaikan penulisan bukunya, selain itu juga dapat mempromosikan institusi tempat bekerja, dan menurunkan tingkat kepikunan dan banyak manfaat lainnya.

Dengan banyaknya manfaat menulis buku akan memberikan motivasi dan keinginan guru untuk belajar menulis buku. Tetapi kenyataannya kebanyakan guru memiliki kesulitan dan hambatan tersendiri dalam menulis buku (Muhtadin dkk, 2020). 
Dari hasil observasi awal guru-guru di Kota Salatiga memiliki kesulitan dan hambatan dalam penulisan buku diantaranya adalah:

1. Tidak fokus dan tidak punya waktu karena terlalu sibuk dengan pekerjaan

2. Bingung dan kurang paham cara dan strategi menulis buku

3. Merasa tidak punya ide dan materi untuk menulis buku

4. Takut salah dan kurang percaya diri

5. Merasa tidak memiliki tata tulis dan tata bahasa yang baik

Dengan permasalahan yang ada tersebut, maka diperlukan solusi melalui pelatihan dan pendampingan penulisan buku. Guru perlu diberikan peningkatan motivasi dan pengetahuan dalam menulis buku (Subaidi, Maswan, \& Wibowo, 2020).

Dengan adanya kondisi wabah pendemi Covid-19 maka kegiatan pelatihan dan pendampingan harus memperhatikan standard keamanan dan protokol kesehatan. Pelatihan online melalui daring merupakan solusi yang dapat digunakan dengan baik. Pelatihan online memiliki kelebihan dapat berjalan kapan saja dan dimana saja dengan tetap memperhatikan protokol kesehatan. Selain itu waktu kegiatan dalam pelatihan online dapat menyesuaikan aktivitas guru. Dengan pelatihan online artinya membutuhkan media yang tepat untuk dapat berkomunikasi via daring. Salah satu media komunikasi Learning Management System (LMS) yang tepat adalah Microsoft Teams. Microsoft Teams adalah hub digital yang menghadirkan percakapan, rapat, file, dan aplikasi dalam pengalaman tunggal di Office 365 Education (Pradja \& Baist, 2019). Kelebihan aplikasi ini adalah mudah pengoperasinya sehingga memberikan kemudahan bagi bapak/ibu guru yang berasal dari berbagai jenjang pendidikan dari guru TK sampai guru SMA yang memiliki kemampuan dasar IT yang berbeda-beda. Microsoft Teams juga memiliki aplikasi video dengan kualitas yang baik dan jernih yang dibutuhkan untuk melakukan web meeting dan pembelajaran (Irredy \& Nungonda, 2019). Kelebihan lainnya adalah kemudahan dalam mengelola kelompok belajar, kemudahan interaksi chat atau diskusi, serta kemudahan pengeditan file dan berbagi file. Kelebihan-kelebihan aplikasi tersebut sangat dibutuhkan sebagai media pendukung dalam pelatihan dan pendampingan pembuatan buku bagi bapak/ibu guru.

Dengan adanya model pelatihan dan pendampingan secara online diharapkan dapat meningkatkan motivasi menulis bagi bapak/ibu guru di Kota Salatiga dan diharapkan dapat meningkatkan kemampuan menulis untuk berbagai macam model buku seperti buku mata pelajaran, buku pengayaan, buku fiksi, dan buku pendukung pembelajaran lainnya. Selain itu setelah dapat menulis dengan baik, guru dapat menerbitkan bukunya untuk di publikasikan dan digunakan untuk khalayak umum.

\section{METODE PELAKSANAAN}

Kegiatan Gerakan Guru Menulis Buku (GGMB) dimulai dengan menganalisis situasi dan kebutuhan kemudian dilanjutkan dengan mendesain model pelatihan dan pendampingan. Dari hasil analisis situasi ditentukan bahwa pelatihan dan pendampingan menulis buku dilakukan dengan online. Kegiatan online ini dilakukan karena kegiatan harus memperhatikan standard protokol kesehatan Covid-19 yang masih mewabah di Indonesia khususnya di Kota Salatiga. Selain itu kegiatan pelatihan 
dan pendampingan online memiliki kelebihan tidak dibatasi oleh waktu dan tempat sehingga bapak/ibu guru dapat berdiskusi, bertanya, belajar kapan saja dan dimana saja. Sedangkan dari hasil analisis kebutuhan memberikan keputusan bahwa:

1. Perlunya memotivasi guru dalam menulis sebagai awal kegiatan agar semangat mengikuti pelatihan terus terjaga.

2. Pelatihan menulis buku diperluas berbagai jenis buku diantaranya buku hasil penelitian, buku ajar atau buku mata pelajaran, buku pengayaan, dan buku fiksi. Hal tersebut karena peserta pelatihan adalah guru dari berbagai jenjang sekolahan sehingga memiliki kebutuhan dan tujuan masing-masing, sekaligus mewadahi berbagai bakat dan talenta menulis dari peserta.

3. Perlunya informasi pengetahuan kaidah terbitan buku dan perlu adanya kerjasama dari penerbit buku agar produk pelatihan ini dapat dipublikasikan.

Dari analisis situasi dan kebutuhan tersebut maka tahap kegiatan pelatihan dan pendampingan di dilakukan sebagai berikut:

\section{Persiapan}

Tahap persiapan dilakukan dengan mencari fasilitator yang tepat sesuai bidangnya, melakukan publikasi kegiatan di berbagai media, melakukan pendaftaran peserta dan menyiapkan media Microsoft Teams untuk kegiatan pelatihan.

\section{Pelatihan dan pendampingan}

Materi pelatihan dan pendampingan mencakup beberapa kegiatan diantaranya:

1. Pelatihan 1 inspirasi dan motivasi menulis

2. Pelatihan 2 menulis buku mata pelajaran

3. Pelatihan 3 menulis buku pengayaan

4. Pelatihan 4 trik mengubah hasil penelitian menjadi buku

5. Pelatihan 5 menulis buku fiksi

6. Pelatihan 6 menerbitkan buku

Masing-masing kegiatan peserta di damping fasilitator yang berpengalaman dan professional dibidangnya masing-masing.

\section{Refleksi dan Evaluasi}

Kegiatan dilakukan diakhir kegiatan untuk mengetahui hasil peningkatan kemampuan menulis guru pada kegiatan pelatihan.

Kegiatan pelatihan dilakukan secara online selama 1 bulan melalui aplikasi Microsoft Teams. Kegiatan meliputi web meeting pemberian materi oleh fasilitator, diskusi forum, penugasan, konsultasi, pendampingan penulisan, dan evaluasi.

\section{HASIL DAN PEMBAHASAN}

Kegiatan Gerakan Guru Menulis Buku dengan pelatihan dan pendampingan ini diikuti 117 peserta dari semua jenjang Pendidikan (tabel 1). Kegiatan ini bertujuan untuk memberikan motivasi menulis buku serta meningkatkan kemampuan menulis buku bagi guru. 
Tabel 1

Peserta kegiatan GGMB

\begin{tabular}{clc}
\hline No & \multicolumn{1}{c}{ Peserta Guru } & Jumlah \\
\hline 1 & TK & 12 \\
2 & SD & 15 \\
3 & SMP & 20 \\
4 & SMA/SMK & 63 \\
5 & Dinas Pendidikan & 7 \\
& Jumlah & 117 \\
\hline
\end{tabular}

Kegiatan ini didampingi oleh 5 fasilitator sesuai bidang keahlian materi masingmasing. Kegiatan pelatihan penulisan buku ini dimulai tanggal 19 Agustus 2020 melalui web meeting dengan aplikasi Microsoft Teams. Fasilitator bapak Arif Ediyanto, M.Pd. yang merupakan owner Rumah Guru memberikan motivasi dan inspirasi terkait publikasi ilmiah dan karya ilmiah kepada bapak/ibu guru peserta kegiatan. Web meeting yang dilakukan selama 2,5 jam ini memberikan semangat dan kemampuan awal dalam menulis buku kepada bapak/ibu guru peserta. Setelah itu peserta melanjutkan diskusi dan konsultasi melalui Microsoft Teams.

Penyampaian materi ke dua yaitu menulis buku mata pelajaran atau buku ajar, yang disampaikan tanggal 21 Agustus 2020 oleh ibu Mistina, S.Pd. Materi yang disampaikan meliputi bagaimanakah trik dan langkah-langkah menulis buku mata pelajaran bagi guru. Penyampaian materi bertujuan untuk meningkatkan kemampuan guru dalam menulis buku mata pelajaran, sehingga harapannya dalam pembelajaran di kelas guru dapat menggunakan buku karyanya sendiri dalam aktivitas mengajar peserta didik. Buku karya guru sendiri akan lebih efektif dan tepat sasaran karena dibuat guru berdasarkan karateristik peserta didik dan kebutuhan pembelajaran yang diperlukan. Setelah kegiatan web meeting peserta melanjutkan diskusi di Microsoft Teams (gambar 1), membahas kendala dan solusi yang harus dilakukan dalam menulis buku mata pelajaran atau buku ajar.

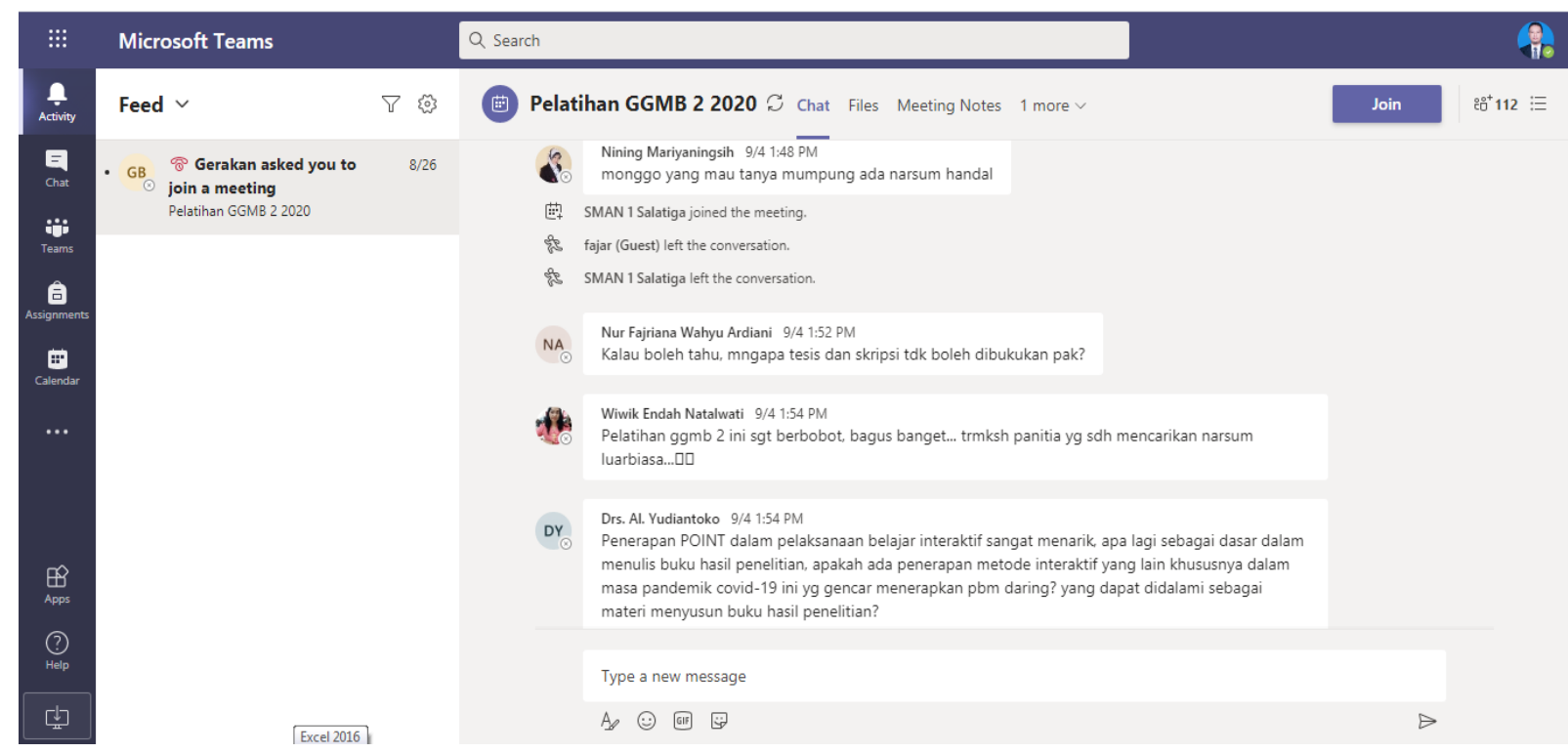

Gambar 1. Kegiatan diskusi melalui Microsoft Teams 
Penyampaian materi ke tiga yaitu menulis buku pengayaan. Materi disampaikan oleh penulis Dr. Suranto, M.Pd. melalui web meeting pada tanggal 26 Agustus 2020 (gambar 2). Materi yang disampaikan diantaranya adalah cara membuat buku pengayaan melalui tiga cara yaitu menulis dengan bahasa sendiri, pengemasan kembali informasi, dan penataan informasi. Guru diberikan penjelasan terkait langkah-langkah membuat buku pengayaan, diantaranya adalah 1) menentukan tujuan membuat buku, 2) mencari ide dan memilah ide, 3) membuat outline kemudian mengembangkan dan menyempurnakannya, 4) melengkapi bahan (buku referensi, internet, slide presentasi, jurnal ilmiah, dll), 5) merancang struktur tulisan, 6) menetapkan alur buku, 6) mulai menulis bagian yang mudah terlebih dahulu, 7) menulis bagian awal buku, 8) menulis bab demi bab, 9) melengkapi gambar, tabel, dll., 10) melakukan editing dan mempercantik tampilan, 11) draf buku di review orang lain 12) cek ulang dan finishing, 13) menyiapkan draf buku ke penerbit.

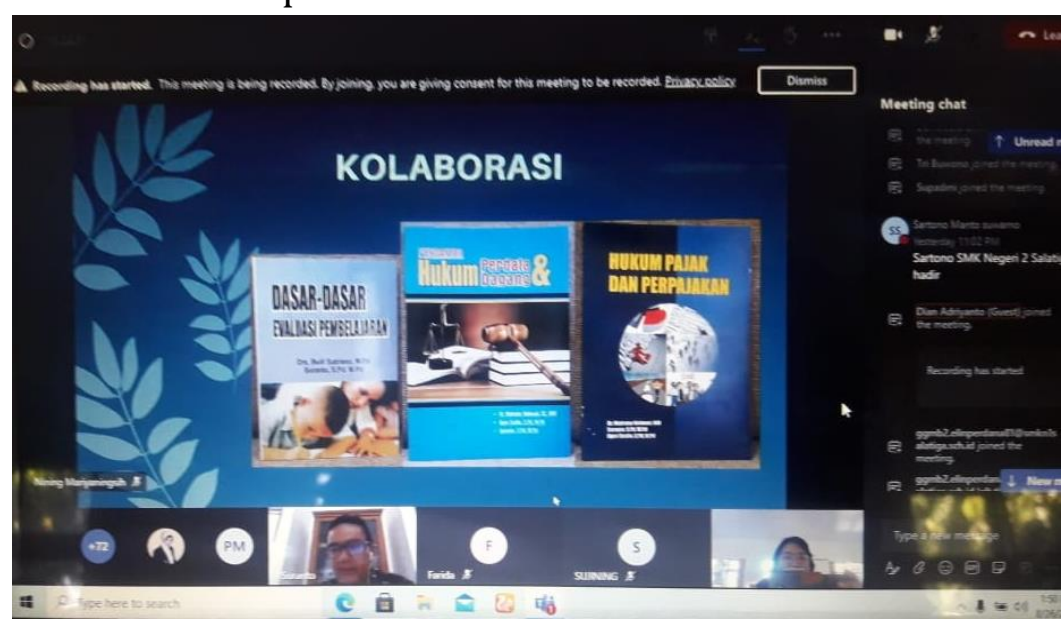

Gambar 2. Kegiatan web meeting melalui aplikasi Microsoft Teams

Materi ke empat adalah trik mengubah hasil penelitian menjadi buku. Fasilitator materi ini adalah Bapak Arif Ediyanto, M.Pd. Pelatihan ini dilaksanakan tanggal 28 Agustus 2020 yang diawali melalui web meeting kemudian dilanjutkan dengan diskusi di LMS Microsoft Teams. Penyampaian materi ke lima adalah menulis buku fiksi. Materi disampaikan oleh ibu Dwi P, S.Pd. Materi yang disampaikan adalah bagaimana menulis buku fiksi diantaranya adalah buku cerpen, buku novel, dan buku puisi. Buku fiksi diharapkan sebagai penyaluran bakat kreatifitas guru dalam bidang yang ditekuni. Buku fiksi juga dapat digunakan sebagai buku pendamping dalam pembelajaran di kelas. Kegiatan pelatihan ini dimulai dengan web meeting pada tanggal 2 September 2020.

Materi ke enam adalah menerbitkan buku, yang disampaikan oleh fasilitator Ibu Nining Mariyaningsih, M.Pd. Kegiatan dilaksanakan tanggal 4 September 2020 melalui web meeting dan diskusi melalui Microsoft Teams. Dalam setiap materi pelatihan penulisan buku, peserta didik dapat terus melakukan diskusi, konsultasi, dan pembimbingan melalui media Microsoft Teams. Kegiatan juga di didukung oleh penerbit buku Embrio Kita yang siap menerbitkan karya peserta kegiatan setelah menyelesaikan penulisan bukunya. 
Diakhir kegiatan hasil evaluasi dan refleksi, peserta kegiatan menyatakan kegiatan ini sangat bermanfaat dalam meningkatkan motivasi dan pengetahuan menulis, draf buku hasil pelatihan dan pendampingan selama kegiatan akan dilanjutkan dan disempurnakan sampai siap untuk diterbitkan. Adanya perubahan pola pikir peserta setelah pelatihan bahwa menulis buku bukanlah hal yang sulit, peserta mendapatkan semangat dan rasa percaya diri yang lebih baik untuk menulis buku. Mereka sadar perlu sedikit menyisihkan waktunya untuk menulis dan harus tetap menjaga motivasi untuk terselesaikannya karya buku yang diinginkan. Peserta juga menyadari bahwa menulis buku tidak harus bersifat individu, tetapi dapat kolaboratif dengan rekan profesinya sehingga akan lebih efisien dan efektif dalam menghasilkan buku.

\section{KESIMPULAN}

Kegiatan pelatihan dan pendampingan penulisan buku sangat diperlukan untuk meningkatkan motivasi dan kemampuan menulis guru. Dengan gerakan guru menulis buku, produktifitas menulis guru dapat ditingkatkan. Peserta pelatihan penulisan buku mendapatkan pengetahuan terkait penulisan buku mata pelajaran, penulisan buku pengayaan, penulisan buku fiksi, dan penulisan buku dari hasil penelitian. Dengan model pembelajaran online menggunakan Microsoft Teams peserta jadi lebih merasa efektif karena waktu yang tidak terbatasi untuk melakukan diskusi, konsultasi, dan pembimbingan. Kegiatan ini dapat dilakukan secara rutin setiap semester atau setiap tahun agar bergantian semua guru dapat mengikutinya, sehingga dapat meningkatkan produktifitas guru dalam menulis buku.

\section{UCAPAN TERIMAKASIH}

Penulis mengucapkan terimakasih kepada panitia Gerakan Guru Menulis Buku (GGMB) ke-2 khususnya kepada SMK N 1 Salatiga yang telah memfasilitasi pelatihan ini sehingga kegiatan berjalan sangat lancar dan berhasil guna.

\section{DAFTAR RUJUKAN}

Haryati, dkk. (2011). Pelatihan penulisan buku ajar bagi guru PKN SMA Se Kota Semarang. E-DIMAS: Education-Pengabdian Kepada Masyarakat, 2 (1), 1-11. DOI: https://doi.org/10.26877/e-dimas.v2i1.100

Ireddy, V. K. \& Nungonda, A. (2019). Microsoft Teams Approaches to Solve Collaboration Needs. International Journal of Computer Applications, 182 (44), 13-16. DOI: https://doi.org/10.5120/ijca2019918561

Jauhar, S., Rukayah, \& Asmah, S. (2019). PKM Pelatihan penulisan bahan ajar IPS bagi guru-guru SD Negeri 13 Biru Kecamatan Tanete Riattang Kabupaten Bone. MATAPPA: Jurnal Pengabdian Kepada Masyarakat, 2 (2), 29-33. DOI: http://doi.org/10.31100/matappa.v2i1.336

Muhtadin, dkk. (2020). Pelatihan dan pendampingan penyusunan bahan ajar bagi guru Pondok Pesantren Mazroillah Kota Lubuklinggau dalam meningkatkan kualitas pembelajaran. Jurnal Cemerlang: Pengabdian pada Masyarakat, 2 (2), 162-172. DOI: https://doi.org/10.31540/jpm.v2i2.903 
Pradja, B.P. \& Baist, A. (2019). Analisis kualitatif penggunaan Microsoft Teams dalam pembelajaran kolaboratif daring. Seminar Nasional Matematika dan Pendidikan Matematika (4th SENATIK), Semarang: 20 Agustus 2019. Hal 415-420.

Sofiah, dkk. (2019). Pelatihan dan pendampingan penyusunan bahan ajar bagi guru SMA 5 Kediri. Jurnal Karinov, 2 (1), 52-56. DOI: http://dx.doi.org/10.17977/um045v2i1p52-56

Subaidi, Maswan, \& Wibowo, P.A. (2020). Pelatihan penulisan buku ajar bagi guru di MA Safinatul Huda Sowan Kidul Kedung Jepara. J-ABDIPAMAS (Jurnal Pengabdian Kepada Masyarakat), 4 (1), 93-98. DOI: http://dx.doi.org/10.30734/jabdipamas.v4i1.862 